Experiment-to-Experiment Disturbance of Microgravity Environment

Richard DeLombard

Lewis Research Center, Cleveland, Ohio

Kenneth Hrovat

Tal-Cut Company, North Olmsted, Ohio

Kevin McPherson

Lewis Research Center, Cleveland, Ohio 
Since its founding, NASA has been dedicated to the advancement of aeronautics and space science. The NASA Scientific and Technical Information (STI) Program Office plays a key part in helping NASA maintain this important role.

The NASA STI Program Office is operated by Langley Research Center, the Lead Center for NASA's scientific and technical information. The NASA STI Program Office provides access to the NASA STI Database, the largest collection of aeronautical and space science STI in the world. The Program Office is also NASA's institutional mechanism for disseminating the results of its research and development activities. These results are published by NASA in the NASA STI Report Series, which includes the following report types:

- TECHNICAL PUBLICATION. Reports of completed research or a major significant phase of research that present the results of NASA programs and include extensive data or theoretical analysis. Includes compilations of significant scientific and technical data and information deemed to be of continuing reference value. NASA's counterpart of peerreviewed formal professional papers but has less stringent limitations on manuscript length and extent of graphic presentations.

- TECHNICAL MEMORANDUM. Scientific and technical findings that are preliminary or of specialized interest, e.g., quick release reports, working papers, and bibliographies that contain minimal annotation. Does not contain extensive analysis.

- CONTRACTOR REPORT. Scientific and technical findings by NASA-sponsored contractors and grantees.
- CONFERENCE PUBLICATION. Collected papers from scientific and technical conferences, symposia, seminars, or other meetings sponsored or cosponsored by NASA.

- SPECIAL PUBLICATION. Scientific, technical, or historical information from NASA programs, projects, and missions, often concerned with subjects having substantial public interest.

- TECHNICAL TRANSLATION. Englishlanguage translations of foreign scientific and technical material pertinent to NASA's mission.

Specialized services that complement the STI Program Office's diverse offerings include creating custom thesauri, building customized data bases, organizing and publishing research results ... even providing videos.

For more information about the NASA STI Program Office, see the following:

- Access the NASA STI Program Home Page at http://www.sti.nasa.gov

- E-mail your question via the Internet to help@sti.nasa.gov

- Fax your question to the NASA Access Help Desk at (301) 621-0134

- Telephone the NASA Access Help Desk at (301) 621-0390

- Write to:

NASA Access Help Desk

NASA Center for AeroSpace Information 7121 Standard Drive

Hanover, MD 21076 
NASA/TM-1998-208847

AIAA-99-0576

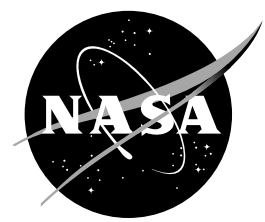

\section{Experiment-to-Experiment Disturbance of Microgravity Environment}

Richard DeLombard

Lewis Research Center, Cleveland, Ohio

Kenneth Hrovat

Tal-Cut Company, North Olmsted, Ohio

Kevin McPherson

Lewis Research Center, Cleveland, Ohio

Prepared for the

37th Aerospace Sciences Meeting and Exhibit

sponsored by the American Institute of Aeronautics and Astronautics

Reno, Nevada, January 11-14, 1998

National Aeronautics and

Space Administration

Lewis Research Center 


\section{Acknowledgments}

The authors would like to acknowledge the contributions of the following mission participants for their part in this activity. Dr. John Lipa, the CHeX PI from Stanford, for whom most of this investigation was done. Dr. Ulf Israelsson, the CHeX Project Scientist from JPL, who assisted with understanding the problem with respect to CHeX. Richard Abramczyk, the IDGE lead engineer with Dynacs at NASA Lewis, who described the IDGE internal fans during the mission. Diane Malarik, the IDGE Project Manager at NASA Lewis, who gave approval for the post-mission test of IDGE with SAMS. The remainder of the $\mathrm{CHeX}$ and IDGE teams with whom we dealt before the mission, during the mission and after the mission. The SAMS team from NASA Lewis for their excellent support during the mission and for conducting the post-mission tests. The PIMS team from NASA Lewis who processed the reams of data, worked with the experiment teams and mission cadre, and diligently monitored the mission activities.

This report contains preliminary

findings, subject to revision as analysis proceeds.

Available from

NASA Center for Aerospace Information 7121 Standard Drive

Hanover, MD 21076

Price Code: A03
National Technical Information Service 5285 Port Royal Road Springfield, VA 22100 Price Code: A03 


\title{
EXPERIMENT-TO-EXPERIMENT DISTURBANCE OF MICROGRAVITY ENVIRONMENT
}

\author{
Richard DeLombard, NASA Lewis Research Center, Cleveland, Ohio \\ Kenneth Hrovat, Tal-Cut Company, North Olmsted, Ohio \\ Kevin McPherson, NASA Lewis Research Center, Cleveland, Ohio
}

\begin{abstract}
The STS- 87 Shuttle mission carried the Fourth United States Microgravity Payload (USMP-4) as one of the primary payloads. Four USMP-4 science experiments were installed on two carriers in the cargo bay of the Shuttle. The Confined Helium Experiment $(\mathrm{CHeX})$, located on the aft carrier, was particularly susceptible to vibrations in several frequency ranges due to structural resonances of the $\mathrm{CHeX}$ apparatus and the extreme sensitivity of the sample to vibrations. Shortly after activation of the USMP-4 payload, a strong vibratory disturbance within the susceptibility region of the $\mathrm{CHeX}$ apparatus was detected. After investigating the characteristics of the disturbance and the time at which it first appeared, it was deduced that the vibration was generated by cooling fans in the Isothermal Dendritic Growth Experiment (IDGE). This paper will summarize the development of the conflict, briefly describe the disturbance source, and the susceptibility of the $\mathrm{CHeX}$ apparatus, and summarize the results of postmission tests of IDGE.
\end{abstract}

\section{ACRONYMS \& ABBREVIATIONS}

$\mathrm{CHeX}$ Confined Helium Experiment

g Earth's gravity level (nominally $9.81 \mathrm{~m} / \mathrm{s}^{2}$ )

IDGE Isothermal Dendritic Growth Experiment

ISS International Space Station

JPL Jet Propulsion Laboratory

$\mu \mathrm{g} \quad 10^{-6}$ times nominal Earth's gravity level

mg $\quad 10^{-3}$ times nominal Earth's gravity level

Copyright $(1999$ by the American Institute of Aeronautics and Astronautics, Inc. No copyright is asserted in the United States under Title 17, U.S. Code. The U.S. Government has a royaltyfree license to exercise all rights under the copyright claimed herein for Government Purposes. All other rights are reserved by the copyright owner.
MPESS Mission Peculiar Equipment Support Structure

PIMS Principal Investigator Microgravity Services

SAMS Space Acceleration Measurement System

STS Space Transportation System

USMP-4 Fourth United States Microgravity Payload

\section{INTRODUCTION}

\section{Science Experiments in Microgravity}

The prime motivation for a scientist to go through the process of taking an experiment into microgravity conditions is to operate that experiment in the absence of the overriding effects of gravity. With the free-fall conditions of an orbiting spacecraft, apparent weightlessness is achieved allowing more subtle effects to be observed, such as the surface tension of liquids, solidification of materials without buoyant settling, and convection-free combustion.

The effects of gravity are seen in Earth-bound laboratories due to restraining forces exerted by containers, such as ampoules, test tubes, or anything that stops a sample from falling. In a condition of free fall, the sample and associated containers do not have a relative force between them since they are both experiencing the same acceleration. A drop tower attains this free fall condition by vertically dropping an experiment sample in a carriage. An aircraft accomplishes a free fall by flying a parabolic trajectory. An Earth-orbiting vehicle attains this free fall condition by balancing the gravitational attraction with a centripetal acceleration obtained by a circular (or nearly circular) orbit. Using these three methods of achieving reduced gravity conditions, scientists have conducted numerous experiments to investigate basic phenomena which are unobservable in the presence of the normal gravitational forces.

American Institute of Aeronautics and Astronautics 
AIAA-99-0576

Gravity is not the only acceleration that disturbs experiments on the ground. Ground-based laboratories have other vibrational disturbances such as elevators, air conditioners, earthquakes, and actions of people. In a similar way, the microgravity environment of the Shuttle has vibrational disturbances, such as pumps, machines, fans, and crew motions.

\section{FOURTH UNITED STATES MICROGRAVITY PAYLOAD}

The STS-87 Shuttle mission from 19 November 1997 to 5 December 1997 carried the Fourth United States Microgravity Payload (USMP-4) as one of the primary payloads. Four USMP-4 science experiments were installed on two Mission Peculiar Equipment Support Structure (MPESS) carriers in the cargo bay of the Shuttle as shown in Figure 1. The Advanced Automated Directional Solidification Furnace and the French-built furnace MEPHISTO were mounted on the forward MPESS carrier. The Confined Helium Experiment $(\mathrm{CHeX})$ and Isothermal Dendritic Growth Experiment (IDGE) were mounted on the aft carrier. Two Space Acceleration Measurement System (SAMS) units were included in the USMP-4 complement, one mounted on each of the two MPESS carriers.

\section{Space Acceleration Measurement System}

The SAMS units measured the microgravity acceleration environment during the on-orbit operations of USMP-4 to record and characterize the conditions under which the experiments were operated. ${ }^{1}$ The Principal Investigator Microgravity Services (PIMS) project team monitored the SAMS data available in realtime during the mission and provided interpretation of the microgravity environment to the Principal Investigator (PI) teams, mission cadre, and other mission participants.

A SAMS unit is comprised of up to three remote triaxial acceleration sensor heads and a main unit which controls the system, records the data, and makes the data available to be transmitted to operations facilities on the ground. Each of the remote sensor heads may be configured with a low-pass filter so as to measure the accelerations in the frequency band of interest to the experiment supported by that sensor head. The standard filter cutoff frequencies available are 2.5, 5, 10, 25, 50, and $100 \mathrm{~Hz}$. Once configured for a Shuttle mission, these frequencies are fixed for that mission.

\section{Confined Helium Experiment}

The Confined Helium Experiment $(\mathrm{CHeX})^{2}$, hnade specific heat measurements on a sample of liquid helium as the sample was heated through its superfluid/fluid transition. The sample was confined to a twodimensional state by silicon plates.

Laboratory experiments to date have yielded inconclusive results about theories of the behavior of confined matter. CHEX made use of high-resolution thermometers and the microgravity environment of the space shuttle to investigate theoretical predictions with accuracy impossible in ground-based experiments.

The core of the experiment is a cylindrical copper calorimeter containing a liquid helium sample. The sample is confined in a two-dimensional state by a stack of 408 parallel silicon wafers. The confined sample is contained in 50 micrometer gaps between the 50 micrometer thick wafers. Heat capacity is measured in a step-wise fashion by injecting heat into the sample and measuring the resultant temperature change using thermometers with temperature resolution on the order of nano-Kelvins. The temperature was approximately 2 Kelvin and the energy input into the sample for each step was measured in pico-watts.

Accurate thermal control of the calorimeter is provided by an apparatus developed for the Lambda Point Experiment, a previous microgravity experiment. The thermal control apparatus, including the calorimeter, is housed in a cryogenic dewar mounted on the MPESS carrier in the Shuttle payload bay.

Due to the sample temperature sensitivity to small energy changes, the structural susceptibility to vibrations was measured in a series of tests. The test results showed that $\mathrm{CHeX}$ was particularly susceptible to vibrations in several frequency ranges due to structural resonances of the $\mathrm{CHeX}$ apparatus, with one such region centered at $55 \mathrm{~Hz}$. As a result, concern was expressed prior to the mission regarding the magnitude of the third harmonic at $51 \mathrm{~Hz}$ of the Shuttle antenna vibration at $17 \mathrm{~Hz}$. Tests to investigate the possible effects from the Ku-band antenna were planned for early in the mission. 
AIAA-99-0576

\section{Isothermal Dendritic Growth Experiment}

The IDGE scientific objective is to test fundamental assumptions concerning dendritic solidification of molten materials. ${ }^{3,}{ }^{4}$ Dendrites are tiny branching structures that form inside molten metal alloys when they solidify. The size, shape, and orientation of the dendrites have a major effect on the strength, ductility, and usefulness of an alloy. Ultimately, information from IDGE may result in improved industrial manufacturing of steel, aluminum, superalloys, and other metals that are used on Earth every day.

The basic IDGE apparatus consists of a thermostat containing a growth chamber, cameras, two slow-scan televisions, an active internal temperature control system, and computer systems. Air fans are used for cooling electronics subassemblies and for ensuring uniformity in the sample temperature. IDGE was flown on USMP-2, USMP-3, and USMP-4.

\section{EXPERIMENT-TO-EXPERIMENT DISTURBANCE}

\section{The Problem}

Due to the known $\mathrm{CHeX}$ susceptibility to vibrations around $55 \mathrm{~Hz}$, tests were planned early in the STS-87 mission to investigate the effect of the Ku band antenna dither frequency. Early in the mission, though, a stronger disturbance was noticed primarily around 56 Hertz which was within the susceptibility region of the $\mathrm{CHeX}$ apparatus. This disturbance first appeared about Mission Elapsed Time (MET) 000/03:25 as shown in Figure 2. The CHeX PI requested that the source of the disturbance be identified with the possibility that it be disabled during critical $\mathrm{CHeX}$ operations.

\section{The Investigation}

The unexpected $56 \mathrm{~Hz}$ vibrations were first noticed using real-time acceleration data downlinked from SAMS. Analyses of the SAMS data were conducted by the PIMS project team over several days to characterize this disturbance according to the expressed needs of the $\mathrm{CHeX}$ PI. The $\mathrm{CHeX}$ team needed to assess the impact of these vibrations on their operations. In order to develop a compensation or mitigation method, the $\mathrm{CHeX}$ PI needed the frequency and magnitude characteristics of the disturbance. A series of data plots was requested by the CHeX PI so the frequency spread and magnitude variation of the disturbance could be examined.

A typical power spectral density (PSD) plot with high frequency resolution representative of the set prepared for the $\mathrm{CHeX} \mathrm{PI}$ is shown in Figure 3. The strength of this disturbance may be seen from the magnitude height of the peaks around $56 \mathrm{~Hz}$ and the frequency width of the disturbance, especially compared with the signal from the third harmonic of the Ku-band antenna dither frequency. The result of the characterization of this disturbance was that the vibrations in the 56 Hertz region were a combination of several sources at slightly different frequencies, with each source at a relatively constant frequency and magnitude. The mission scientist consulted with the various experiment teams, Spacelab support staff, and Orbiter subsystem personnel to ascertain the source of these disturbances.

After investigating the characteristics of the 56 Hertz disturbance and, in particular, the time at which it first appeared, the PIMS team deduced that the vibration may have been introduced by the IDGE apparatus. In discussions with IDGE personnel, it was found that within the IDGE apparatus there were six cooling fans and a fan whose speed was controlled by a measured internal IDGE temperature.

The generation of vibrations at these frequencies by the IDGE apparatus was not noticed in SAMS data from the USMP-2 and USMP-3 payloads because lower frequency sensor heads were utilized for those missions. Lower frequency SAMS sensor heads were chosen because the experiments on those missions (including IDGE) were susceptible only to lower frequency disturbances. Data plots were prepared from SAMS data from USMP-2 and USMP-3 but were rather inconclusive due to the severe attenuation at the higher frequencies.

During testing at NASA Kennedy Space Center, $\mathrm{CHeX}$ had observed an effect to their experiment from both SAMS and IDGE. To confirm that SAMS was not contributing to the $56 \mathrm{~Hz}$ disturbance, one of the SAMS units was turned off for several minutes during USMP-4. No significant effect was found from this de-activation of SAMS. It was decided that the IDGE would not be 
AIAA-99-0576

turned off due to the risks to IDGE science operations if there were problems with re-activating IDGE.

\section{The Resolution}

The resolution of the potential problem during the mission was for $\mathrm{CHeX}$ to compensate their data for this $56 \mathrm{~Hz}$ disturbance. Compensation was possible in part due to the constant frequency and reasonably constant amplitude nature of the disturbance. If the disturbance had been of a variable frequency or variable magnitude, the compensation would have been more difficult, if not impossible. That situation may have resulted in major conflict of operations between IDGE and CHeX.

\section{End-of-mission Test}

In an effort to gain final confirmation of the source of the $56 \mathrm{~Hz}$ disturbances, the deactivation of the USMP4 experiments was conducted sequentially with call downs from the crew as to the times of each step. The SAMS data around the IDGE deactivation time on MET day 015 are shown as a spectrogram in Figure 4. In addition to the $56 \mathrm{~Hz}$ traces, the variable trace between 35 and $40 \mathrm{~Hz}$, and a $74 \mathrm{~Hz}$ disturbance cease at the time of the IDGE power-off at about MET 015/09:47.

\section{Post-mission Tests}

After the experiments were de-integrated from the carriers at the end of the mission, a test was performed at LeRC with the SAMS flight instrument and the IDGE flight apparatus. The intent of this test was to confirm or disprove the deduction formed during the mission that the IDGE apparatus was responsible for these vibrations.

The SAMS data for this ground test are shown as a spectrogram in Figure 5 with the major activities indicated. The fans causing the disturbance around $56 \mathrm{~Hz}$ begin operation as soon as IDGE power is turned on at about 8 minutes and turn off when the IDGE power is turned off at about 90 minutes. Notice that the frequency varies slightly when the fans first begin, but then the frequency remains essentially stable. The $74 \mathrm{~Hz}$ disturbance turns on and off with the IDGE computer power on and off. The source of the variable frequency disturbance at around $80 \mathrm{~Hz}$ is unknown. The variable frequency disturbance between 30 and $50 \mathrm{~Hz}$ appears to be related (as suspected during the mission) with the
IDGE temperature-controlled fan. These post-mission test characteristics match well with the observed characteristics of the disturbances during the mission.

\section{LESSONS LEARNED AND RE-EMPHASIZED}

Analysis and test of an experiment's susceptibility to vibrations is important when the experiment is being designed and constructed. In this case, the CHeX team was prepared at the beginning of their operations to examine the microgravity acceleration environment to determine if it met their requirements.

In mission planning, adjacent or nearby experiments need to critically examine their 'neighbors' for possible sources of vibrations that may be disturbances. CHeX made measurements during ground testing at NASA Kennedy Space Center to ascertain the effect of SAMS and IDGE on their operations.

Acceleration measurements need to be made with bandwidth that includes the susceptibility regions of an experiment. The disturbance around $56 \mathrm{~Hz}$ was not apparent in the SAMS data from two previous missions because lower frequency sensor heads were used in those missions. Even by examining that data processed out to the Nyquist frequency, the disturbance was not apparent. Measurement with a sensor head of sufficient bandwidth on USMP-4 made the disturbance very clear.

The acceleration environment data needs to be examined as soon as it is available even if the experiment appears to be operating satisfactorily. The $\mathrm{CHeX}$ data from USMP-4 appeared nominal during initial operations, but the disturbance was noticed in the SAMS data. There would have been serious impact on the $\mathrm{CHeX}$ data if the disturbance had been unnoticed and the magnitude and/or frequency had not stayed steady.

It should be noted that there were no vibration limit requirements imposed by NASA Johnson Space Center on the USMP-4 payload nor by the USMP-4 payload on the individual experiments. Thus, in this situation, there was no experiment at fault. Rather it was fortunate that the acceleration data was available in real-time, the problem was recognized, and a resolution was obtained early in the mission. 


\section{CONCLUSIONS}

This experiment-to-experiment disturbance episode illustrates a potential problem for microgravity science experiment operations on the International Space Station. In the design of the experiment, the hardware design team must consider not only vibrations caused by the experiment itself and by the vehicle, but must also consider vibrations caused by other experiments.

A PI's familiarity with the microgravity environment, their experiment's susceptibility, and vibration isolation systems may help to alleviate some of the problems of experiment-to-experiment disturbances. The PI team must assess the susceptibility of their experiment to accelerations, considering steady, slowly varying, oscillatory, and transient accelerations. Appropriate measures should then be taken for the measurement of the environment during the experiment operations. The environment should be examined as soon as practical relative to the experiment operations and data analysis.

This problem emphasizes two points for future microgravity science experiments conducted on the Shuttle or the International Space station. The first point is that the real-time acquisition and interpretation of microgravity acceleration data may be essential to the success of an experiment. The second point is that the sub-allocation of vibration limits down to the experiment level is important for a research platform such as the International Space Station.

\section{ACKNOWLEDGMENTS}

The authors would like to acknowledge the contributions of the following mission participants for their part in this activity.

Dr. John Lipa, the CHeX PI from Stanford, for whom most of this investigation was done. Dr. Ulf Israelsson, the CHeX Project Scientist from JPL, who assisted with understanding the problem with respect to CHeX. Richard Abramczyk, the IDGE lead engineer with Dynacs at NASA Lewis, who described the IDGE internal fans during the mission. Diane Malarik, the IDGE Project Manager at NASA Lewis, who gave approval for the post-mission test of IDGE with SAMS. The remainder of the $\mathrm{CHeX}$ and IDGE teams with whom we dealt before the mission, during the mission and after the mission. The SAMS team from NASA Lewis for their excellent support during the mission and for conducting the post-mission tests. The PIMS team from NASA Lewis who processed the reams of data, worked with the experiment teams and mission cadre, and diligently monitored the mission activities.

\section{REFERENCES}

1) Rogers, M. J. B., et. al.: Summary Report of Mission Acceleration Measurements for STS-87, NASA Technical Memorandum in preparation.

2) $\mathrm{CHeX}$ information on the World Wide Web: http://chex.stanford.edu/

3) USMP-4: The Final Round of a Great Series, Microgravity News, Fall 1997:

http://mgnwww. larc.nasa.gov/fall97/ lead.html

4) IDGE information on the World Wide Web: http://zeta.lerc.nasa.gov/expr2/idge.htm http://www.rpi.edu/locker/56/000756/index.html 


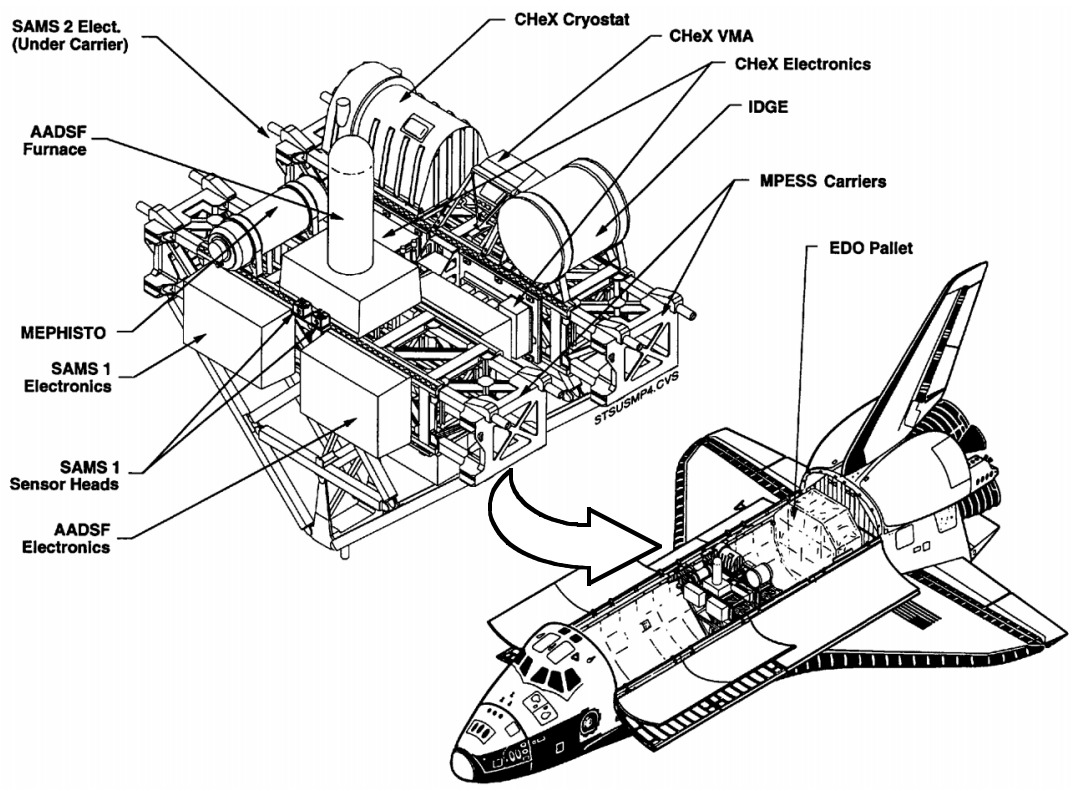

Figure 1: $\quad$ USMP-4 MPESS in cargo bay

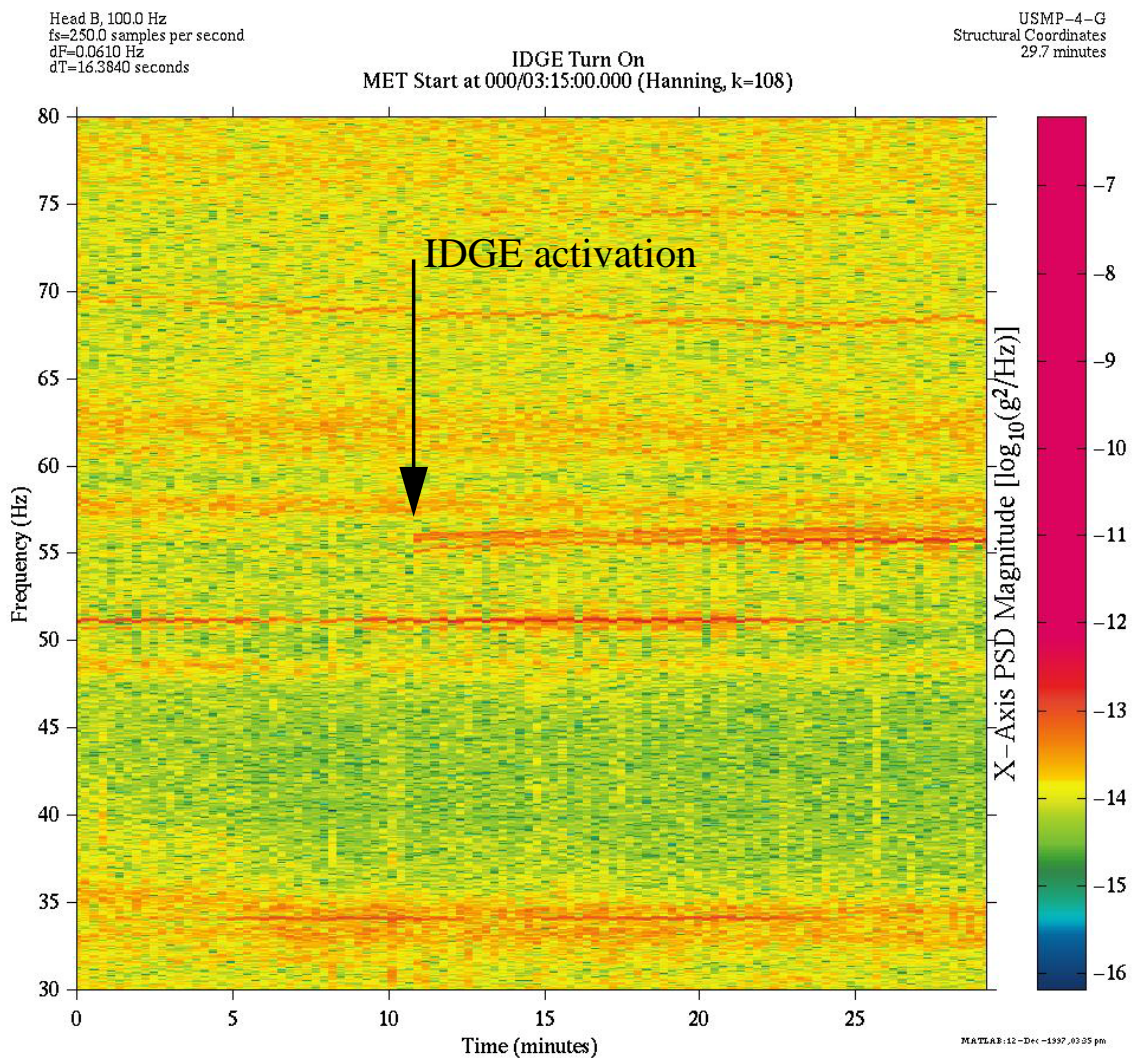

Figure 2: $\quad$ Spectrogram showing initiation of $56 \mathrm{~Hz}$ signal 


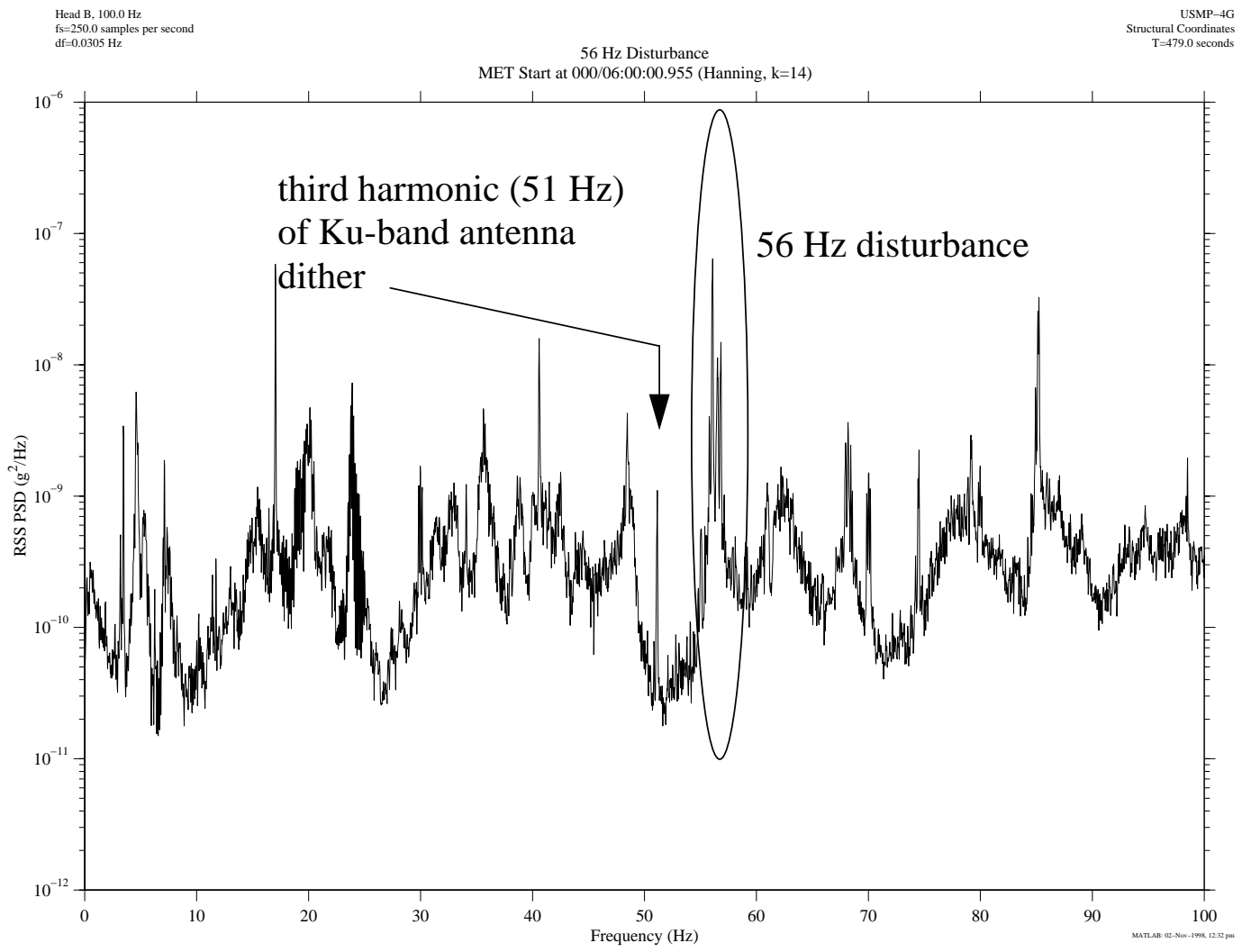

Figure 3: High resolution power spectral density plot prepared for CHeX PI

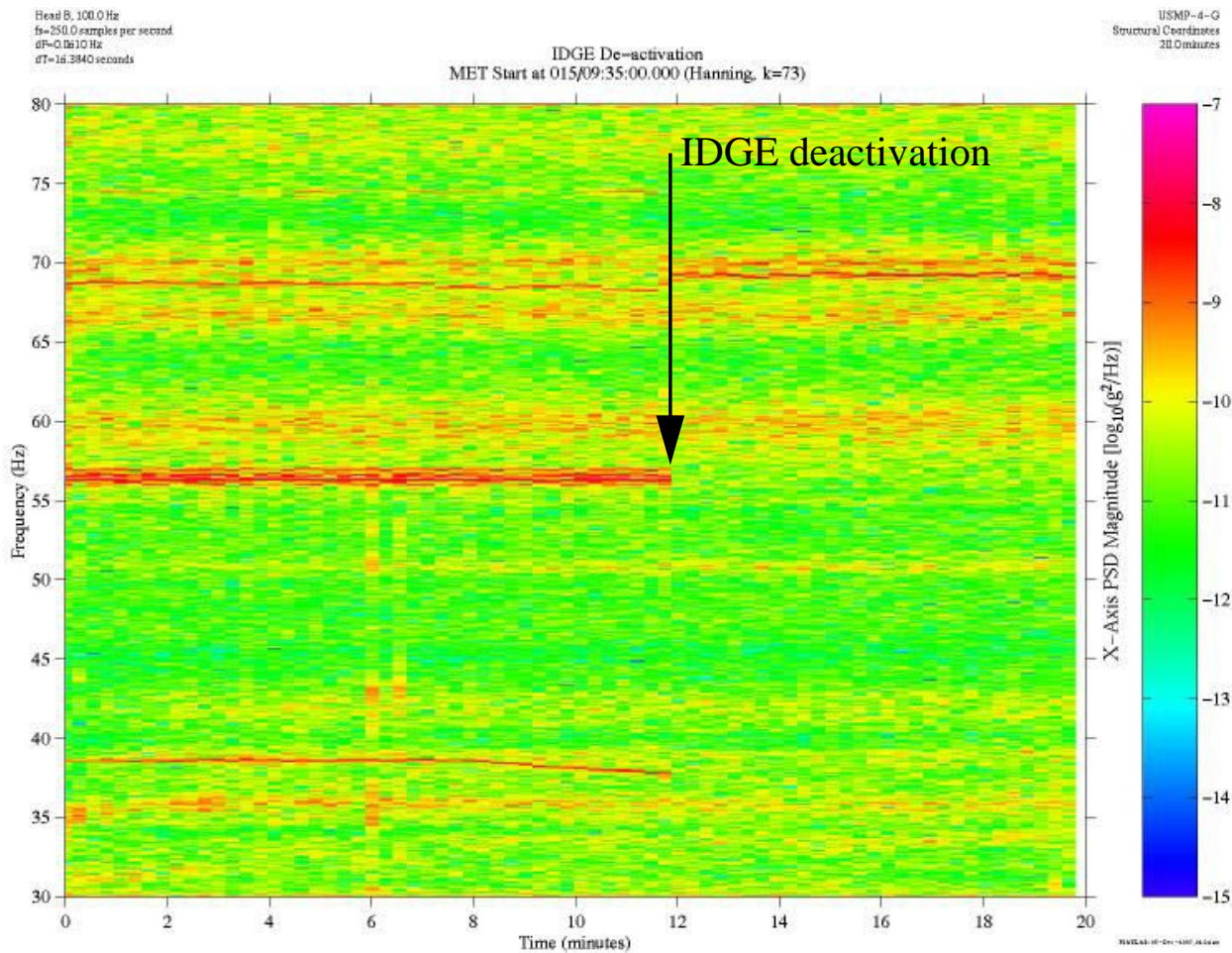

Figure 4: Deactivation of IDGE near end of mission 


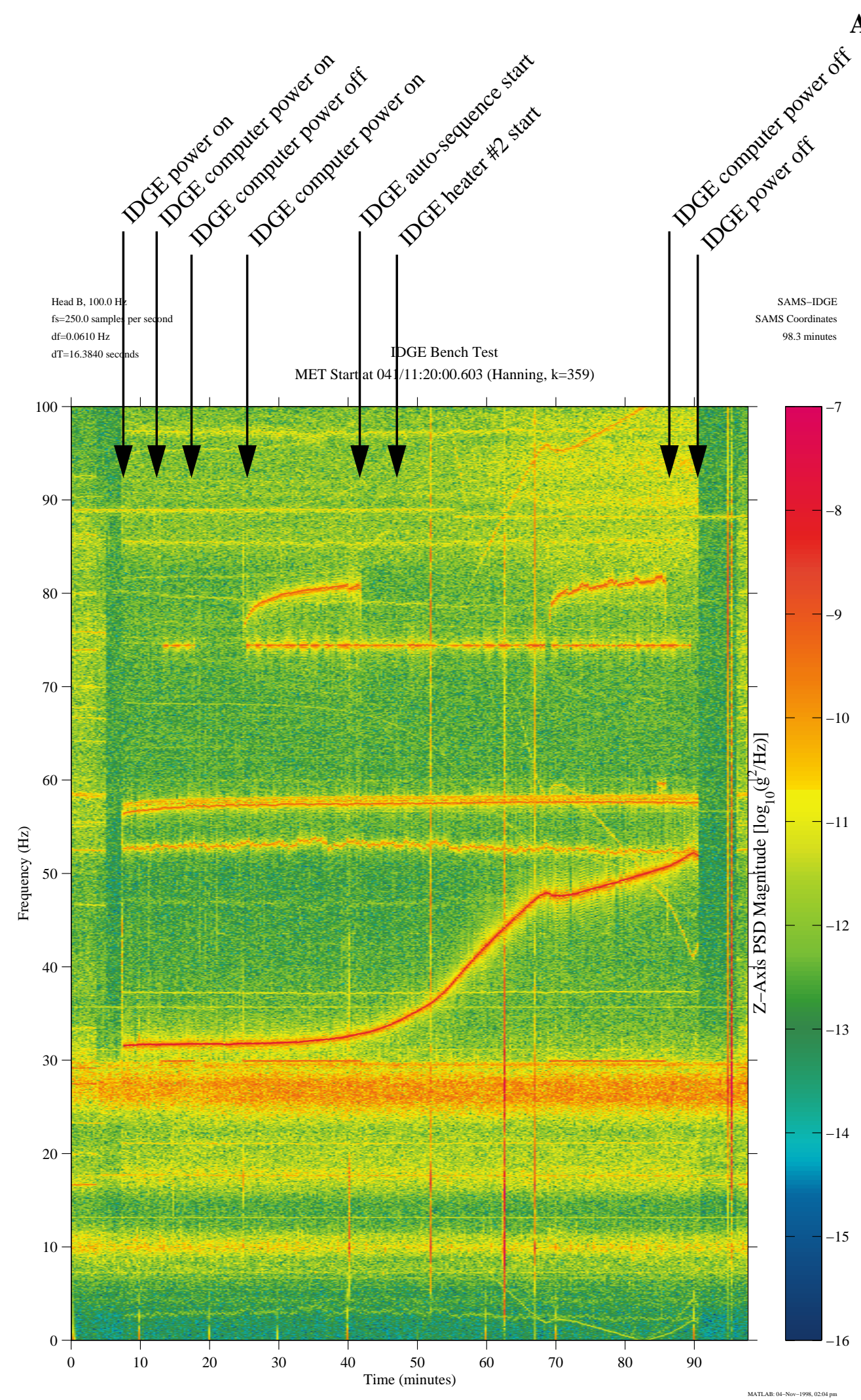

Figure 5: Spectrogram of SAMS data during post-mission laboratory test 
Public reporting burden for this collection of information is estimated to average 1 hour per response, including the time for reviewing instructions, searching existing data sources, gathering and maintaining the data needed, and completing and reviewing the collection of information. Send comments regarding this burden estimate or any other aspect of this collection of information, including suggestions for reducing this burden, to Washington Headquarters Services, Directorate for Information Operations and Reports, 1215 Jefferson Davis Highway, Suite 1204, Arlington, VA 22202-4302, and to the Office of Management and Budget, Paperwork Reduction Project (0704-0188), Washington, DC 20503.

\begin{tabular}{|l|c|c|}
\hline 1. AGENCY USE ONLY (Leave blank) & $\begin{array}{c}\text { 2. REPORT DATE } \\
\text { December } 1998\end{array}$ & $\begin{array}{r}\text { 3. REPORT TYPE AND DATES COVERED } \\
\text { Technical Memorandum }\end{array}$
\end{tabular}

4. TITLE AND SUBTITLE 5. FUNDING NUMBERS

Experiment-to-Experiment Disturbance of Microgravity Environment

6. $\operatorname{AUTHOR(S)}$

WU-398-95-0G-00

Richard DeLombard, Kenneth Hrovat, and Kevin McPherson

7. PERFORMING ORGANIZATION NAME(S) AND ADDRESS(ES)

8. PERFORMING ORGANIZATION

National Aeronautics and Space Administration

Lewis Research Center

Cleveland, Ohio 44135-3191

REPORT NUMBER

E-11465

9. SPONSORING/MONITORING AGENCY NAME(S) AND ADDRESS(ES)

National Aeronautics and Space Administration

Washington, DC 20546-0001

10. SPONSORING/MONITORING

AGENCY REPORT NUMBER

NASA TM-1998-208847

AIAA-99-0576

11. SUPPLEMENTARY NOTES

Prepared for the 37th Aerospace Sciences Meeting \& Exhibit sponsored by the American Institute of Aeronautics and

Astronautics, Reno, Nevada, January 11-14, 1999. Richard DeLombard, NASA Lewis Research Center; Kenneth Hrovat,

Tal-Cut Company, 24831 Lorain Road, Suite 203, North Olmsted, Ohio, 44070 (work funded under NAS3-27254); and

Kevin McPherson, NASA Lewis Research Center. Responsible person, Richard DeLombard, organization code 6727, (216) 433-5285.

\begin{tabular}{|l|l|l|l|} 
12a. DISTRIBUTION/AVAILABILITY STATEMENT & DISTRIBUTION CODE
\end{tabular}

Unclassified - Unlimited

Subject Categories: 19 and $35 \quad$ Distribution: Nonstandard

This publication is available from the NASA Center for AeroSpace Information, (301) 621-0390.

13. ABSTRACT (Maximum 200 words)

The STS-87 Shuttle mission carried the Fourth United States Microgravity Payload (USMP-4) as one of the primary payloads. Four USMP-4 science experiments were installed on two carriers in the cargo bay of the Shuttle. The Confined Helium Experiment $(\mathrm{CHeX})$, located on the aft carrier, was particularly susceptible to vibrations in several frequency ranges due to structural resonances of the $\mathrm{CHeX}$ apparatus and the extreme sensitivity of the sample to vibrations. Shortly after activation of the USMP-4 payload, a strong vibratory disturbance within the susceptibility region of the CHeX apparatus was detected. After investigating the characteristics of the disturbance and the time at which it first appeared, it was deduced that the vibration was generated by cooling fans in the Isothermal Dendritic Growth Experiment (IDGE). This paper will summarize the development of the conflict, briefly describe the disturbance source, and the susceptibility of the $\mathrm{CHeX}$ apparatus, and summarize the results of post-mission tests of IDGE.

14. SUBJECT TERMS

Microgravity environment; SAMS; Orbiter; Acceleration measurement 15. NUMBER OF PAGES

17. SECURITY CLASSIFICATION OF REPORT

Unclassified
18. SECURITY CLASSIFICATION OF THIS PAGE

Unclassified
19. SECURITY CLASSIFICATION OF ABSTRACT

Unclassified
14

16. PRICE CODE

$\mathrm{A} 03$

20. LIMITATION OF ABSTRACT

Standard Form 298 (Rev. 2-89)

Prescribed by ANSI Std. Z39-18 298-102 